\title{
CLOSED NEWTON COTES QUADRATURE RULES WITH DERIATIVES
}

\author{
Ariba Khatri \\ Department of Basic Sciences and Related Studies \\ Mehran University of Engineering and Technology \\ Jamshoro, Sindh, Pakistan \\ Asif Ali Shaikh \\ Department of Basic Sciences and Related Studies \\ Mehran University of Engineering and \\ Technology \\ Jamshoro, Sindh, Pakistan \\ Kashif Ali Abro \\ Department of Basic Sciences and Related Studies \\ Mehran University of Engineering and Technology \\ Jamshoro, Sindh, Pakistan
}

\begin{abstract}
In this research paper, a new family of numerical integration of closed newton cotes is introduced which uses the mean of arithmetic and geometric means at derivative value for the Evaluation of Definite Integral. These quadrature methods are shown to be more efficient than the existing quadrature rules. The error terms are obtained by using the concept of precision. Finally, the accuracy of proposed method is verified with numerical examples and the results are compared with existing methods numerically and graphically.
\end{abstract}

Keywords - Numerical Integration, Closed Newton-cotes formula, Definite integral, Arithmetic mean, Geometric mean, Numerical examples.

DOI: 10.7176/MTM/9-5-06

Publication date: May $31^{\text {st }} 2019$

1.1 INTRODUCTION: In numerical Analysis, Numerical Integration is a significant subfield and has wide variety of Algorithms for calculating different types of Integrals [1]. It has various Applications in the field of Physics and Engineering. To find area under a curve (shown below), To find velocity and to find surface are some applications.

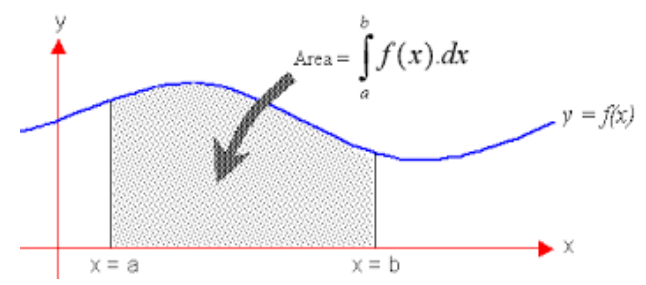

In the field of Mathematics, to achieve the high precision numerical integration formulas becomes one of the challenges [2]. The Newton-Cotes formulas are the most common numerical integration schemes [5]. It is assumed that the value of a function $\mathrm{f}(\mathrm{x})$ defined on $[a, b]$ is known at equally spaced points $\mathrm{x}_{i}$, for $\mathrm{i}=0,1,2---, \mathrm{n}$, 
where $\mathrm{x}_{0}=\mathrm{a}$ and

$\mathrm{x}_{\mathrm{n}}=\mathrm{b}$. The general form for closed Newton cotes of degree $\mathrm{n}$ is stated as

$\int_{a}^{b} f(x) d x \approx \sum_{i=0}^{n} w_{i} f\left(x_{i}\right)$

Where there are $(n+1)$ distinct points, such that $a=x_{0}<x_{1}<\cdots x_{n}=b, x_{i}=x_{0}+i h, i=0,1,2, \cdots n$, and $(n+1)$ weights $\mathrm{w}_{0}, \mathrm{w}_{1}, \cdots \mathrm{w}_{\mathrm{n}}$, also $\mathrm{h}=\frac{\mathrm{b}-\mathrm{a}}{\mathrm{n}}$. These weights can be calculated by two ways. [ 9 ]

The first way is to interpolate $\mathrm{f}(\mathrm{x})$ at $(\mathrm{n}+1)$ points $\mathrm{x}_{0}, \mathrm{x}_{1, \ldots} \mathrm{x}_{\mathrm{n}}$, using the Lagrange polynomials and then integrating the foresaid polynomial to obtain 1.The second method is based on the precision of Quadrature formula. Select the values for $\mathrm{w}_{\mathrm{i}}$ so that the error of approximation in the Quadrature formula is zero, i-e

$E_{n}[f]=\int_{a}^{b} f(x) d x-\sum_{i=0}^{n} w_{i} f\left(x_{i}\right)=0$

Where $f(x)=x^{j}, j=0,1,2 \cdots n$.

An integration method of the form 1 is said to be of order $P$ if it produces accurate results $E_{n}[f]=0$ for all polynomials of degree less than or equal to P. [10]

Some of the closed Quadrature formula are derived depending on different values of $n$. For $\mathrm{n}=1$ : Trapezoidal rule $\quad \int_{a}^{b} f(x) d x=\frac{b-a}{2}[f(a)+f(b)]-\frac{(b-a)^{3}}{12} f^{\prime \prime}(\xi)$, where $\xi \epsilon(a, b)$

For $\mathrm{n}=2$ :Simpson's $1 / 3^{\text {rd }}$ rule $\quad \int_{a}^{b} f(x) d x=\frac{b-a}{6}\left[f(a)+4 f\left(\frac{a+b}{2}\right)+f(b)\right]-\frac{(b-a)^{5}}{2880} f^{4}(\xi)$, where $\xi \epsilon(a, b)$

...(

It is known that the degree of precision is $(n+1)$ for even values of $n$ 's and $n$ for odd values of $n$ 's. [6]

Several works have been carried out to improve the order of accuracy of the existing newton cotes rules. Dehghan, M., Masjed-Jamei, M. and Eslahchi, M.R [6,7,8] improved closed, open and semi-open newton cote's formula by including the location of boundaries of the interval as two additional parameter and rescaling the original integral to fit the optimal boundary. Clarence O.E Burg [3] introduced a different approach by using first and higher order derivatives at the evaluation locations within the closed newton cote's quadrature in order to increase the precision and order of accuracy. Clarence and Ezachiel[4] introduced derivative based midpoint quadrature rule for improvement of the existing formula. Weijing Zhoe and Hongxing Li[17] improved the closed newton cote's Quadrature formula by putting in the midpoint derivative. T.Ramchandra et al[11,12,13,14,15,16] used the technique of Weijing and they applied this technique by using Geometric mean, harmonic mean, Heronian mean , centroidal mean, root mean square. The motivation of this research paper is to introduce new derivative-based closed cotes Rules for numerical integration which uses mean of arithmetic mean and geometric mean at derivative value. These schemes are discussed in section 1.1.1 and in section 1.1.2, the error terms for the proposed schemes are also derived. Lastly the numeric examples are solved to show the effectiveness of the proposed schemes in section 1.1.3.

\subsubsection{METHODOLOGY}

In this Section, A new formula is derived by using mean of arithmetic mean and geometric mean at the terminal points $[a, b]$ in Newton cotes quadrature formula for the evaluation of a definite integral.

$>$ Closed Trapezoidal rule $(\mathrm{n}=1)$ using mean of arithmetic and geometric means is

$\int_{a}^{b} f(x) d x=\frac{b-a}{2}[f(a)+f(b)]-\frac{(b-a)^{3}}{12} f^{\prime \prime}\left(\frac{a+2 \sqrt{a b}+b}{4}\right)$

The precision of this method is 2 .

Proof: For $\mathrm{f}(\mathrm{x})=\mathrm{x}^{2}$ 
The exact value of $\int_{a}^{b} x^{2} d x=\frac{1}{3}\left(b^{3}-a^{3}\right)$

By using (7), $\frac{b-a}{2}\left(a^{2}+b^{2}\right)-\frac{2(b-a)^{3}}{12}=\frac{1}{3}\left(b^{3}-a^{3}\right)$.

The solution is exact. Thus, the precision of the closed Trapezoidal rule with mean of A.M and G.M is 2 whereas the precision of the existing Trapezoidal rule (3) is 1

$>$ Closed Simpson's $1 / 3^{\text {rd }}$ rule $(\mathrm{n}=2)$ using mean of arithmetic and geometric means is

$\int_{a}^{b} f(x) d x=\frac{b-a}{6}\left[f(a)+4 f\left(\frac{a+b}{2}\right)+f(b)\right]-\frac{(b-a)^{5}}{2880} f^{4}\left(\frac{a+2 \sqrt{a b}+b}{4}\right)$

The precision of this method is 4 .

Proof: For $\mathrm{f}(\mathrm{x})=\mathrm{x}^{4}$.

The exact value of $\int_{a}^{b} x^{4} d x=\frac{1}{5}\left(b^{5}-a^{5}\right)$;

By using (8), $\frac{b-a}{6}\left[a^{4}+4\left(\frac{a+b}{2}\right)^{4}+b^{4}\right]-\frac{24(b-a)^{5}}{2880}=\frac{1}{5}\left(b^{5}-a^{5}\right)$.

It shows that the solution is exact. Thus, the precision of the closed Simpson's $1 / 3^{\text {rd }}$ rule with mean of arithmetic and geometric means is 4 whereas the precision of the existing Simpson's $1 / 3^{\text {rd }}$ rule (4) is 3 .

\subsubsection{ERROR TERMS OF THE PROPOSED METHOD}

In this section, the error terms for the mean of arithmetic and geometric means derivative -based closed newton cotes quadrature rule is derived. The error terms can be calculated by different ways. Here error terms are obtained by using the difference between the quadrature formula for the monomial $\frac{x^{p+1}}{p+1}$ and the exact result $\frac{1}{(p+1) !} \int_{a}^{b} x^{p+1} d x$, where $\mathrm{p}$ is the precision of the quadrature formula.

$>$ The error term for Trapezoidal rule $(\mathrm{n}=1)$ is $\mathrm{E}_{1}[\mathrm{f}]=-\frac{(b-a)^{3}}{48}(\sqrt{b}-\sqrt{a})^{2} f^{3}(\xi)$ where $\xi \epsilon(a, b)$

Proof: Let $\mathrm{f}(\mathrm{x})=\mathrm{x}^{3} / 3 !, \int_{a}^{b} x^{3} d x=\frac{1}{4 !}\left(b^{4}-a^{4}\right)$;

Using $5, \frac{b-a}{3 ! 2}\left[b^{3}+a^{3}-(b-a)^{2}\left(\frac{a+2 \sqrt{a b}+b}{4}\right)\right]$

Therefore,

$\frac{1}{4 !}\left(b^{4}-a^{4}\right)-\frac{b-a}{3 ! 2}\left[b^{3}+a^{3}-(b-a)^{2}\left(\frac{a+2 \sqrt{a b}+b}{4}\right)=-\frac{(b-a)^{3}}{48}(\sqrt{b}-\sqrt{a})^{2}\right.$

The error term for Simpson's $1 / 3^{\text {rd }}(\mathrm{n}=2)$ is $\mathrm{E}_{2}[\mathrm{f}]=-\frac{(b-a)^{5}}{11520}(\sqrt{b}-\sqrt{a})^{2} f^{5}(\xi)$ where $\xi \epsilon(a, b)$

Proof: Let $\mathrm{f}(\mathrm{x})=\mathrm{x}^{5} / 5 !, \int_{a}^{b} x^{5} d x=\frac{1}{720}\left(b^{6}-a^{6}\right)$;

Using $6, \frac{b-a}{5 ! .6}\left[a^{5}+b^{5}+4\left(\frac{a+b}{2}\right)^{5}-\frac{(b-a)^{4}}{4}\left(\frac{a+2 \sqrt{a b}+b}{4}\right)\right]$

Therefore, 
$\frac{1}{6 !}\left(b^{6}-a^{6}\right)-\frac{b-a}{5 ! .6}\left[a^{5}+b^{5}+4\left(\frac{a+b}{2}\right)^{5}-\frac{(b-a)^{4}}{4}\left(\frac{a+2 \sqrt{a b}+b}{4}\right)\right]=-\frac{(b-a)^{5}}{11520}(\sqrt{b}-\sqrt{a})^{2}$

\subsubsection{Numerical Examples;}

In this section, some integrals are computed in oder to compare the effectiveness of Closed Newton Cotes formula and the proposed method.

Example \# 1: $\int_{0}^{2} e^{x} d x=6.389056$

(Zhao and Li 2013; T.Ramachandran et al 2016)

Example \# 2: $\int_{0}^{\pi / 2} \sin x d x=1.000000$

Example \# 3: $\int_{0}^{2} e^{-x^{2}} d x=0.8820813908$

(Burg 2012; Burg and Degny 2013)

Example \#4 $\int_{0}^{1} \frac{\ln (1+x)}{1+x} d x=0.2402265070$

Since the exact results for integral in example 3 is not available, this example is approximated to 10 significant digits as shown above.In table 1-4 examples (1-4) are solved by new scheme and compared with Existing for $n=1$ case (Trapezoidal) respectively. In tables 5-8 the same examples (1-4) are solved and compared for $n=2$ case (Simpson's $1 / 3^{\text {rd }}$ ) respectively. The Number of Iteration shows the Number of equally spaced sub-intervals for composite rules. In graphs the Absolute error are compared for case 1 and case 2 (Fig 1-4) for all the above examples. The Absolute error is defined as |Exact value - Approximated value|.

\begin{tabular}{|l|l|l|l|l|}
\hline Table 1 & \multicolumn{2}{|l|}{ Trapezoidal } & Modified Trapezoidal \\
\hline Iterations & Approximate value & Error & Approximate value & Error \\
\hline $\mathrm{N}=1$ & 8.389056 & 2.000000 & 7.289909 & 0.900853 \\
\hline $\mathrm{N}=2$ & 6.91281 & 0.523754 & 6.448014 & 0.058958 \\
\hline $\mathrm{N}=3$ & 6.623953 & 0.234897 & 6.417623 & 0.028567 \\
\hline $\mathrm{N}=4$ & 6.52161 & 0.132554 & 6.401012 & 0.011956 \\
\hline $\mathrm{N}=5$ & 6.474017 & 0.084961 & 6.39066 & 0.001604 \\
\hline
\end{tabular}

\begin{tabular}{|l|l|l|l|l|}
\hline Table 2 & Trapezoidal rule & Modified Trapezoidal \\
\hline Iterations & Approximate value & Error & Approximate value & Error \\
\hline $\mathrm{N}=1$ & 0.785398 & 0.214602 & 0.908998 & 0.091002 \\
\hline $\mathrm{N}=2$ & 0.948059 & 0.051941 & 0.992694 & 0.007306 \\
\hline $\mathrm{N}=3$ & 0.977049 & 0.022951 & 0.998389 & 0.001611 \\
\hline $\mathrm{N}=4$ & 0.987116 & 0.012884 & 0.999454 & 0.000546 \\
\hline $\mathrm{N}=5$ & 0.991762 & 0.008238 & 0.999765 & 0.000235 \\
\hline
\end{tabular}




\begin{tabular}{|l|l|l|l|l|}
\hline Table 3 & \multicolumn{2}{|l|}{ Trapezoidal rule } & Modified Trapezoidal \\
\hline Iterations & Approximate value & Error & Approximate value & Error \\
\hline $\mathrm{N}=8$ & 0.8817037913 & $3.775995 \times 10^{-4}$ & 0.8822541954 & $1.728046 \times 10^{-4}$ \\
\hline $\mathrm{N}=16$ & 0.8819862453 & $9.51455 \times 10^{-5}$ & 0.8820911872 & $9.7964 \times 10^{-6}$ \\
\hline $\mathrm{N}=32$ & 0.8820575578 & $2.3833 \times 10^{-5}$ & 0.8820819715 & $5.807 \times 10^{-7}$ \\
\hline $\mathrm{N}=64$ & 0.8820754296 & $5.9612 \times 10^{-6}$ & 0.8820814261 & $3.53 \times 10^{-8}$ \\
\hline $\mathrm{N}=128$ & 0.8820799003 & $1.4905 \times 10^{-6}$ & 0.8820813929 & $2.1 \times 10^{-9}$ \\
\hline
\end{tabular}

\begin{tabular}{|l|l|l|l|l|}
\hline Table 4 & Trapezoidal rule & \multicolumn{2}{l|}{ Modified Trapezoidal } \\
\hline Iterations & Approximate value & Error & Approximate value & Error \\
\hline $\mathrm{N}=1$ & 0.1732867951 & 0.0669397119 & 0.2822452121 & 0.0420187051 \\
\hline $\mathrm{N}=2$ & 0.2217984336 & 0.0184280734 & 0.2458659429 & 0.0056394359 \\
\hline $\mathrm{N}=3$ & 0.2318479079 & 0.0083785991 & 0.2417327799 & 0.0015062729 \\
\hline $\mathrm{N}=4$ & 0.2354730396 & 0.0047534674 & 0.2407908564 & 0.0005643494 \\
\hline $\mathrm{N}=5$ & 0.2371718306 & 0.0030546764 & 0.2404849029 & 0.0002583959 \\
\hline
\end{tabular}

\begin{tabular}{|l|l|l|l|l|}
\hline Table 5 & \multicolumn{2}{|l|}{ Simpsons 1/3 } & \multicolumn{2}{l|}{ Modified Simpsons 1/3 } \\
\hline Iterations & Approximate value & Error & Approximate value & Error \\
\hline $\mathrm{N}=1$ & 6.420728 & 0.031672 & 6.402409 & 0.013353 \\
\hline $\mathrm{N}=2$ & 6.39121 & 0.002154 & 6.389274 & 0.000218 \\
\hline $\mathrm{N}=3$ & 6.389489 & 0.000433 & 6.389076 & 0.00002 \\
\hline $\mathrm{N}=4$ & 6.389194 & 0.000138 & 6.389060 & 0.000004 \\
\hline $\mathrm{N}=5$ & 6.389113 & 0.000057 & 6.389057 & 0.000001 \\
\hline
\end{tabular}

\begin{tabular}{|l|l|l|l|l|}
\hline Table 6 & \multicolumn{2}{|l|}{ Simpsons $1 / 3^{\text {rd }}$} & \multicolumn{2}{l|}{ Modified Simpsons $1 / 3^{\text {rd }}$} \\
\hline Iterations & Approximate value & Error & Approximate value & Error \\
\hline $\mathrm{N}=1$ & 1.002280 & 0.002280 & 1.001009 & 0.00109 \\
\hline $\mathrm{N}=2$ & 1.000135 & 0.000135 & 1.000020 & 0.000020 \\
\hline $\mathrm{N}=3$ & 1.000026 & 0.000026 & 1.000002 & 0.000002 \\
\hline $\mathrm{N}=4$ & 1.000008 & 0.000008 & 1.000000 & 0 \\
\hline $\mathrm{N}=5$ & 1.000003 & 0.000003 & 1.000000 & 0 \\
\hline
\end{tabular}




\begin{tabular}{|l|l|l|l|l|}
\hline Table 7 & \multicolumn{2}{|l|}{ Simpsons 1/3 ${ }^{\text {rd }}$} & Modified Simpsons $1 / 3^{\text {rd }}$ \\
\hline Iterations & Approximate value & Error & Approximate value & Error \\
\hline $\mathrm{N}=8$ & 0.8820803966 & $9.942 \times 10^{-7}$ & 0.8820810096 & $3.812 \times 10^{-7}$ \\
\hline $\mathrm{N}=16$ & 0.8820813286 & $6.22 \times 10^{-8}$ & 0.8820813855 & $5.3 \times 10^{-9}$ \\
\hline $\mathrm{N}=32$ & 0.8820813869 & $3.9 \times 10^{-9}$ & 0.8820813907 & $1 \times 10^{-10}$ \\
\hline $\mathrm{N}=64$ & 0.8820813905 & $3 \times 10^{-10}$ & 0.8820813908 & 0 \\
\hline $\mathrm{N}=128$ & 0.8820813907 & $1 \times 10^{-10}$ & 0.8820813908 & 0 \\
\hline
\end{tabular}

\begin{tabular}{|l|l|l|l|l|}
\hline Table 8 & \multicolumn{2}{|l|}{ Simpsons $1 / 3^{\text {rd }}$} & \multicolumn{2}{l|}{ Modified Simpsons 1/3 } \\
\hline Iterations & Approximate value & Error & Approximate value & Error \\
\hline $\mathrm{N}=1$ & 0.2379689798 & 0.0022575272 & 0.2430485380 & 0.002822031 \\
\hline $\mathrm{N}=2$ & 0.2400312416 & 0.0001952654 & 0.2403412102 & 0.0001147032 \\
\hline $\mathrm{N}=3$ & 0.2401845816 & 0.0000419254 & 0.2402411278 & 0.0000146208 \\
\hline $\mathrm{N}=4$ & 0.2402128028 & 0.0000137042 & 0.2402297025 & 0.0000031955 \\
\hline $\mathrm{N}=5$ & 0.2402208042 & 0.0000057028 & 0.2402274641 & 0.0000009571 \\
\hline
\end{tabular}

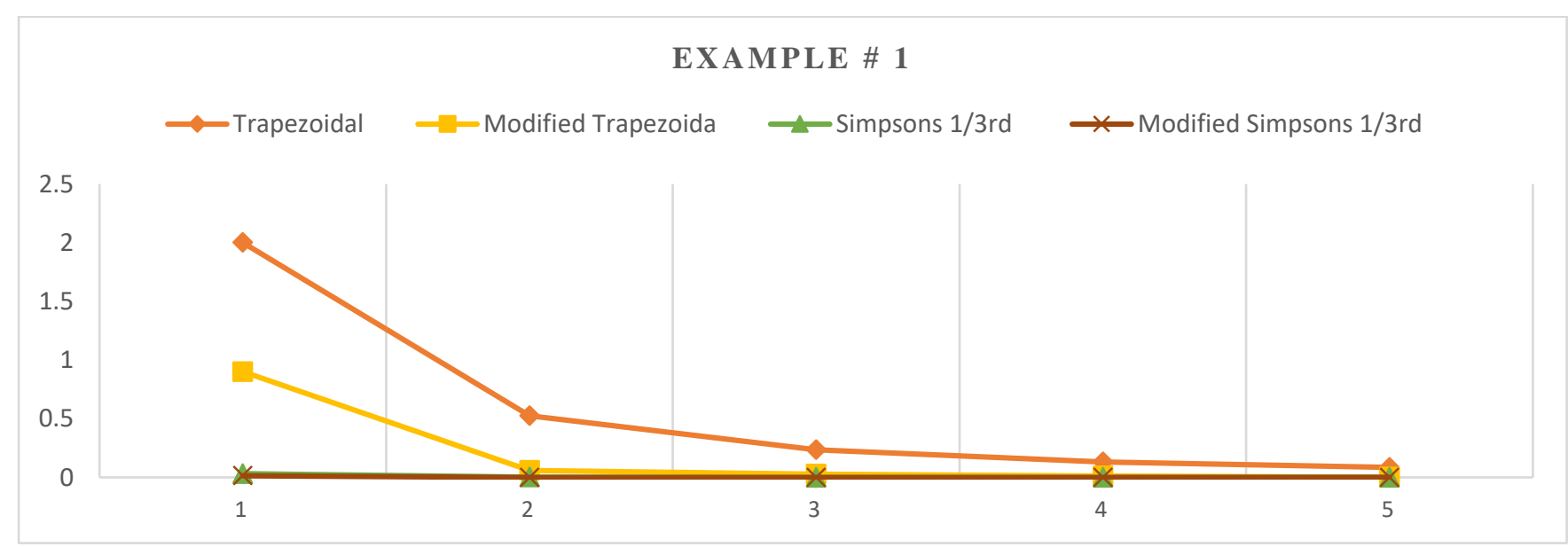




\section{EXAMPLE \# 2}
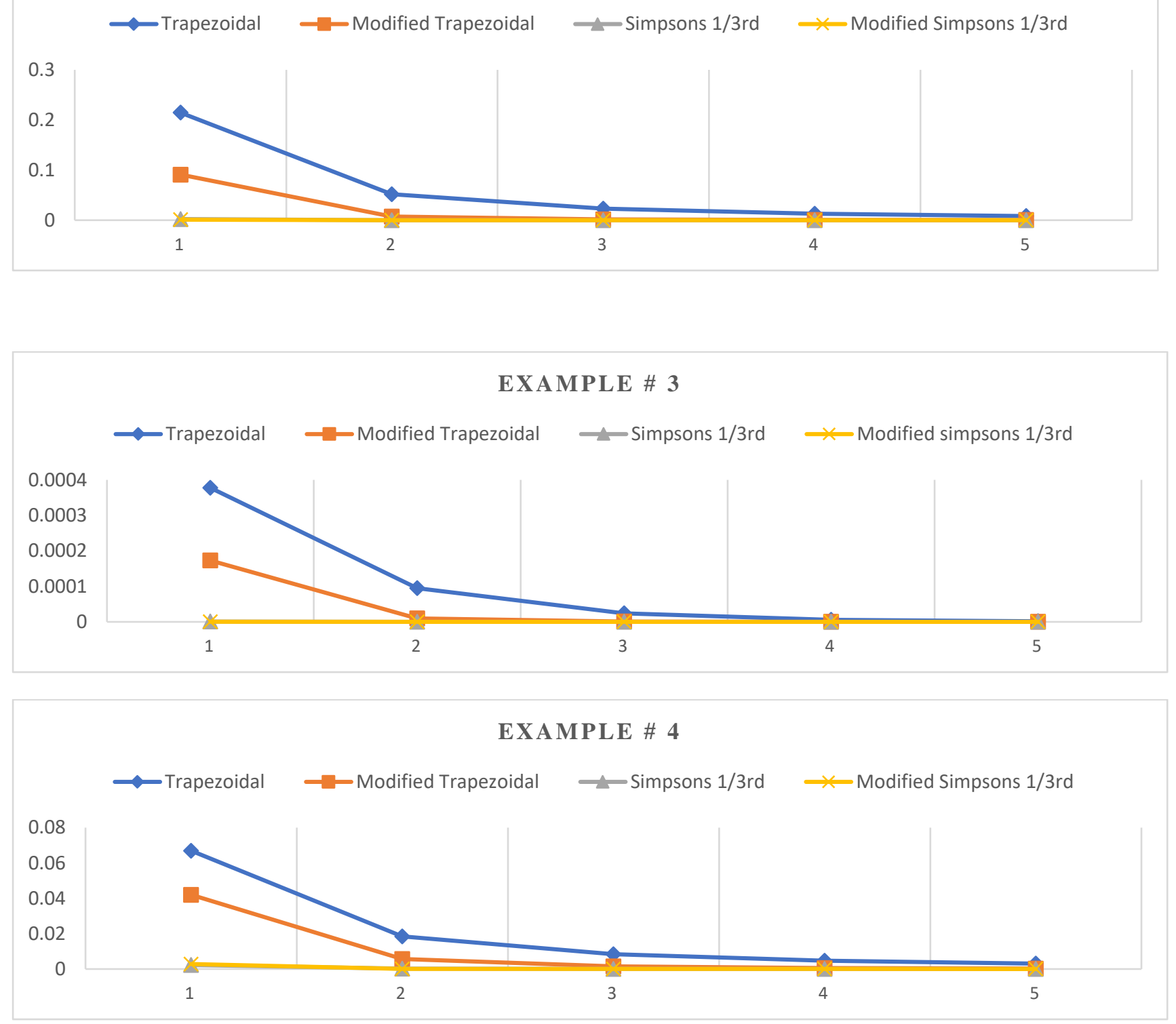

1.1.4 CONCLUSION: The conclusion of this paper can be summarized as

A new family of numerical integration of closed newton cotes is introduced which uses the mean of arithmetic and geometric means at derivative value. It is proved that the proposed method is more efficient than classical newton closed formulas. The error terms are calculated by using the concept of precision. The numerical values are also given to show the accuracy of the proposed method.

\section{REFERENCES}

[1] Atkinson, K.E. (1989) An Introduction to Numerical Analysis. 2nd Edition, John Wiley \& Sons. New York

[2] Bailey, D.H. and Borwein, J.M., 2011. High-precision numerical integration: Progress and challenges. Journal of Symbolic Computation, 46, pp.741-754.

[3] Burg, C.O., 2012. Derivative-based closed Newton-Cotes numerical quadrature. Applied Mathematics and Computation, 218(13), pp.7052-7065. 
[4] Burg, C.O. and Degny, E., 2013. Derivative-based midpoint quadrature rule. Applied Mathematics, 4(01), p.228.

[5] Chapra, S.C. and Canale, R.P., 2010. Numerical methods for engineers. Boston: McGraw-Hill Higher Education.

[6] Dehghan, M., Masjed-Jamei, M. and Eslahchi, M.R., 2005. On numerical improvement of closed NewtonCotes quadrature rules. Applied Mathematics and Computation, 165(2), pp.251-260.

[7] Dehghan, M., Masjed-Jamei, M. and Eslahchi, M.R., 2006. On numerical improvement of open NewtonCotes quadrature rules. Applied mathematics and computation, 175(1), pp.618-627.

[8] Dehghan, M., Masjed-Jamei, M. and Eslahchi, M.R., 2005. The semi-open Newton-Cotes quadrature rule and its numerical improvement. Applied mathematics and computation, 171(2), pp.1129-1140.

[9] KRYLOV, V. I. (1962). Approximate calculation of integrals. New York, Macmillan.

[10] M.K.Jain, S.R.Iyenger and R.K.Jain, (2007), Numerical methods for scientific and computation, New Age International (P) limited, Fifth Edition

[11] Ramachandran, T., Udayakumar, D. and Parimala, R., 2016. Geometric mean derivative-based closed Newton cotes quadrature. International Journal of Pure \& Engineering. Mathematics, 4, pp.107-116.

[12] Ramachandran, T., Udayakumar, D. and Parimala, R., 2016. "Harmonic mean derivative -based closed Newton cotes quadrature ", IOSR - Journal of Mathematics", Vol.12, pp. 36 - 41.

[13] Ramachandran, T., Udayakumar, D. and Parimala, R., 2016. Centroidal mean derivative-based closed Newton cotes quadrature. International Journal of Science and Research, 5, pp.338-343.

[14] Ramachandran, T., Udayakumar, D. and Parimala, R., 2016. • HERONIAN MEAN DERIVATIVE-BASED CLOSED NEWTON COTES QUADRATURE. International Journal of Mathematical Archive EISSN 2229$5046,7(7)$.

[15] Ramachandran, T., Udayakumar, D. and Parimala, R., 2016. Comparison of Arithmetic Mean, Geometric Mean and Harmonic Mean Derivative-Based Closed Newton Cotes Quadrature. Progress in Nonlinear dynamics and Chaos, 4, pp.35-43.

[16] Ramachandran, T., Udayakumar, D. and Parimala, R., 2017. Contra-harmonic mean derivative-based closed newton Cotes quadrature. Global Journal of Pure and Applied Mathematics, 13(5), pp.1319-1330.

[17] Zhao, W. and Li, H., 2013. Midpoint derivative-based closed Newton-Cotes quadrature. In Abstract and Applied Analysis (Vol. 2013). Hindawi. 